Tavares, P. H. - Vocabulário metapsicológico de Freud

\title{
vocabulário metapsicológico de Sigmund Freud: da língua alemã às suas traduções
}

\author{
Sigmund Freud's metapsychological vocabulary: \\ from the German language to its translations
}

\author{
Pedro Heliodoro M. B. Tavares ${ }^{1}$
}

\begin{abstract}
The following article aims to discuss the ground vocabulary of Freudian Metapsychology, beyond the conception of a simple and stiff collection of technique terms. Facing the fact that Freud was a brilliant writer and a keen explorer of the resources provided by the German language, we intend to demonstrate some distortions his vocabulary and style underwent after its passage through internationally influent translations into English and French. Therefore, since recently his work went into the public domain and finally it begins to be directly translated into Portuguese, it is a capital challenge to Freud's translators in Brazil to recover the lifelike face of his words not disregarding the accuracy of his propositions.
\end{abstract}

Key-words: Freud's Vocabulary - Freud's Translations - Freud and the German language Translation and Psychoanalysis.

Resumo: O presente artigo objetiva uma discussão sobre o vocabulário fundamental da Metapsicologia freudiana, para além da concepção de um simples e estanque agrupado de termos técnicos. Levando-se também em consideração o fato de que Freud foi um escritor brilhante e um perspicaz explorador dos recursos oferecidos pela língua alemã, é nossa intenção demonstrar certas distorções de seu estilo e vocabulário sofridas após ter passado por traduções internacionalmente influentes para as línguas inglesa e francesa. Logo, com a recente entrada da obra freudiana para o domínio público, esta finalmente passou a ser traduzida diretamente para o português, tornando-se atualmente um desafio fundamental aos tradutores brasileiros de Freud recuperar a vivacidade de suas palavras sem deixar de levar em consideração a acuidade de suas proposições.

Palavras-chave: Vocabulário de Freud - Traduções de Freud - Freud e a língua alemã Tradução e Psicanálise.

1 Professor da Área de Alemão do DLM-FFLCH-USP, Doutor em Teoria Literária - UFSC, Doutor em Psicanálise e Psicopatologia - Université Paris VII, Pós-Doutorado em Estudos da Tradução PGET/UFSC. Email: pht@usp.br 
Tavares, P. H. - Vocabulário metapsicológico de Freud

Toda área do conhecimento que se desenvolve a partir de determinados escritos capitais tende também a se constituir com base em uma articulação de conceitos fundamentais, de uma terminologia específica. A Terminologia, por sua vez, além do seu sentido de conjunto de conceitos de determinada área ou teoria é também o nome pelo qual é conhecido um campo do conhecimento, uma área de elevada importância para os Estudos da Tradução, sobretudo no que diz respeito aos textos científicos. Tratar-se-ia, a Terminologia grafada com inicial maiúscula, de uma "disciplina científica que estuda as chamadas línguas (ou linguagens) de especialidade e seu vocabulário" (BARROS 2004: 21) visando, sobretudo à uniformidade e à eficiência nos processos tradutórios de textos de especialidades.

Como disciplina científica, a Terminologia teria surgido em Viena a partir das proposições do engenheiro Eugen WÜsTER, que nos anos trinta do século XX funda a Escola Terminológica de Viena, tendo legado à disciplina uma primordial Teoria Geral da Terminologia (id.: 25). Quase coetâneo e concidadão de Wüster e sua nascente disciplina foi, portanto, Sigmund Freud com suas teorias sobre o psiquismo humano e uma técnica destinada ao seu tratamento. Na verdade, Freud estava em sua última década de trabalho e de vida quando surgiriam as propostas de Wüster. Isso quer dizer que muito das preocupações com sistematizações terminológicas ou terminográficas e suas possíveis traduções são posteriores às reflexões freudianas ${ }^{2}$.

Freud dedicou sua carreira intelectual e sua obra escrita à construção de um campo do saber, de uma Ciência, como ele se referia à Psicanálise; e parece de elevada importância no momento atual a renovação de uma discussão a respeito da sua terminologia, de seu vocabulário especializado, quando, a partir de 2009, suas obras entram para o domínio público e, finalmente, temos a oportunidade de ver surgirem as primeiras versões diretas ${ }^{3}$ de seus escritos para a língua portuguesa. Ao mesmo tempo, sabemos que a discussão em torno do vocabulário freudiano envolve aspectos muito mais complexos do que a mera identificação de um conjunto de termos técnicos. Ao lermos um texto desse autor nos confrontamos, para muito além de um pensée pensée,

2 Apontamos a proximidade entre Wüster e Freud por se tratarem de concidadãos contemporâneos e não por ter havido alguma referência de um acerca do trabalho do outro.

3 As duas compilações disponíveis da obra de Freud em língua portuguesa ao longo do século vinte foram elaboradas de modo indireto, a partir do francês (Editora Delta) e do inglês (Editora Imago). 
Tavares, P. H. - Vocabulário metapsicológico de Freud

das típicas exposições objetivas e inequívocas do pensamento científico, com um pensée pensante de um mestre da escrita, da crítica, da reflexão. Os escritos de Freud refletem uma experiência de um saber em formação e em constante revisão, a partir do qual nem sempre é simples um posicionamento relativo a quais vocábulos devem ser elevados à categoria de conceito.

Valendo-se sempre de sua grande erudição e de ensinamentos obtidos das mais diversas áreas do conhecimento, em seu trabalho Über die Psychotherapie (Sobre a psicoterapia) (1905) Freud se vale das observações de outro gênio eclético, Leonardo da Vinci, para estabelecer um símile entre o trabalho analítico e a escultura, sua grande paixão de colecionador. Na escultura, diferentemente da pintura, que opera per via di porre, ajuntando as cores à tela vazia, o trabalho se daria per via di levare, retirando-se do bloco bruto todos os excessos, para que fique somente a forma essencial almejada. Nesse sentido, tanto na sua técnica quanto nas suas proposições teóricas, Freud buscava algo além de acrescentar mais e mais conceitos, regras e axiomas, promovendo um acúmulo de fórmulas e termos. Assim como o trabalho de análise visava à remoção dos excessos, livrando o analisante dos sentidos e sofrimentos excedentes e inconscientemente auto-impostos, seus escritos - via de regra amparados numa estilística apurada que unia beleza e razão - estavam mais comprometidos em desvencilhar o leitor de concepções e conceitos equivocados, do que em apresentar novos conceitos a serem incorporados e admitidos.

Raramente um escrito do criador da Psicanálise pode ser lido como mero texto técnico-descritivo, o que até hoje faz com que seus leitores se aproximem de sua obra também pela via da Literatura, da ensaística ou da crítica cultural. Walter MUSCHG, em seu histórico ensaio Freud als Schriftsteller (Freud como escritor) declara que o escritor Freud não poderia ser separado do cientista (1930: 303) e, nesse sentido, faz coro com a impressão de outros grandes nomes da Literatura e da cultura de expressão alemãs. Thomas MANN teria afirmado em seu ensaio Freud und die Zukunft: "Freud schreibt überhaupt in eine höchst anschauliche Prosa, er ist ein Künstler des Gedankens wie Schopenhauer und wie er ein europäischer Schriftsteller"” (1955: 499). Einstein em carta a Freud declara: "Ganz besonders bewundere ich Ihre Leistung, wie alle Ihre Schriften, vom schriftstellerischen Standpunkt aus. Ich kenne keinen Zeitgenossen, der

4 "Freud escreve de modo geral em uma prosa de forte cunho ilustrativo, é um artista do pensamento tal qual Schopenhauer e, como ele, um escritor europeu." 
Tavares, P. H. - Vocabulário metapsicológico de Freud

in deutscher Sprache seine Gegenstände so meisterhaft dargestellt hat." (apud SCHÖNAU 2006: 265). Hermann HESSE, por fim, teria escrito em resenha à Neue Rundschau: "Sein Werk überzeugt auch außerhalb der Gilde durch ganz hohe menschliche wie literarische Qualitäten. [...] Der sorgfältige Forscher und klare Logiker Freud hat sich ein vorzügliches Instrument in seiner ganz intellektualistischen, aber prachtvoll scharfen, genau definierenden, gelegentlich auch kampf- und spottlustigen Sprache geschaffen ${ }^{6}$ " [Id.]

Quer dizer, através de sua refinada prosa, Freud supera em muito o objetivismo formal dos cientistas ou filósofos com suas articulações terminológicas, o que também não implica dizer que o autor estaria descomprometido com o rigor intelectual e que deveria ser relegado simplesmente ao plano da beletrística. Se muitos justificam a aproximação de Freud da Literatura, e com isso quase um decorrente afastamento do científico, por ele ter sido o agraciado com o Prêmio Goethe em 1930, valeria lembrar que, mais do que um prêmio "literário", este era destinado aos grandes nomes da cultura que, tais com Goethe, desenvolviam um pensamento movidos por uma curiosidade que atravessava fronteiras entre Literatura, Ciência, Política, Filosofia, etc.

O Prêmio Goethe, ao contrário do que muitos pensam, não é literário. Embora a maioria dos agraciados com essa distinção tenham sido escritores e poetas, o prêmio já foi concedido ao arquiteto Walter Gropius (1961), ao cineasta sueco Ingmar Bergman (1976) e à dançarina e coreógrafa Pina Bausch (2008), entre outros. (BRACCO 2011: 253)

Como esclarece Walter PLÄNKERS, o prêmio é destinado a "reconhecidas personalidades, cujas realizações criadoras são dignas de honrar a memória de Goethe" (PlÄNKERS 1993:169 apud BRACCO 2011: 253). Se o primeiro a ganhar o prêmio foi Stefan George, um poeta; o segundo foi um médico que também se ocupou da Música e da Filosofia, a saber, Albert Schweitzer. Entre a Medicina de sua formação e prática profissional, e a prosa que lhe rendeu o reconhecimento até mesmo dos maiores escritores contemporâneos seus, é comum se comentar que Freud jamais teria recebido

\footnotetext{
5 "Admiro especialmente sua produção/realização (Leistung), como a todos os seus escritos, do ponto de vista literário. Não conheço nenhum contemporâneo nosso que apresentou seus objetos de investigação com tanta maestria na língua alemã."

6 "Sua obra desperta convicção também fora do seu milieu devido às suas elevadas qualidades tanto humanas quanto literárias. [...] O Freud pesquisador esmerado, lógico da clareza, criou um instrumento privilegiado em uma linguagem altamente intelectualizada, mas também de um agudo esplendor, de exata definição, bem como de lúdica capacidade combatida e satírica."
} 
Tavares, P. H. - Vocabulário metapsicológico de Freud

o Prêmio Nobel por ter sido "demasiado médico" para receber o de Literatura, e “demasiado literário" para receber o de Medicina.

Freud foi agraciado na quarta edição do Prêmio Goethe, segundo Alfons Paquet, membro do Kuratorium responsável, muito mais em decorrência de sua "afinidade espiritual" com o talentoso, ousado e influente Goethe do que unicamente por seus méritos como escritor: "Die Ihnen zugedachte Ehrung gilt im gleichen Masse dem Gelehrten wie dem Schriftsteller und dem Kämpfer, der in unserer, von brennenden Fragen bewegten Zeit dasteht als ein Hinweis auf eine der lebendigsten Seiten des Goetheschen Wesens $^{7 \%}$ (in FrEUD 1930: 546). Talvez aí a identificação com o pensamento do inquieto, combativo, polêmico Freud mais lembre uma personagem de Goethe, seu Fausto, do que o próprio intelectual que dá nome à premiação.

Goethe, autor do drama sobre o doutor pactário, foi o "autor literário" mais citado por Freud em seus símiles teóricos, mas era também o grande investigador da natureza (Geologia, Botânica, Teoria das Cores) contribuindo com tais características para se tornar, ao lado do também tão genial como polivalente Leonardo, um modelo intelectual para Freud desde os tempos de juventude. A bem da verdade, são os três, Goethe, Leonardo e Freud, espíritos fáusticos que não se conformam aos limites acadêmicos, estilísticos dessa ou daquela área específica do saber ou do fazer.

Não à toa utilizei como epígrafe ao livro Versões de Freud - Breve panorama crítico das traduções de sua obra um dos mais famosos versos do Fausto de Goethe: "Du gleichst dem Geist, den du begreifst, nicht mir", sem apresentar uma tradução. O verso perde muito em qualquer tradução e não somente em sua beleza sonora e aliterantes. Se numa tradução mais direta teríamos: "Igualas o espírito que apreendes, não a mim", não seriam essas uma solução simples, na passagem de uma língua à outra, para os dois verbos e para o único substantivo aí presentes. Pedimos aqui licença para certa digressão no tocante aos elementos dessa frase que nos serão úteis em nossas questões sobre o vocabulário freudiano.

Comecemos pelo complexo caso do substantivo Geist, vocábulo tão comum para o falante nativo da língua alemã e ironicamente tão fugidio para aquele que busque traduzi-lo. Na passagem do drama em que aparece a frase, Fausto se vê desiludido por

7 "A homenagem que lhe é destinada, vale tanto ao intelectual, quanto ao escritor e ao combatente, que em nossos tempos abalados por cáusticas questões, afirma-se como referência de uma das faces mais vivas do espírito/ser (Wesen) goethiano." 
Tavares, P. H. - Vocabulário metapsicológico de Freud

não poder absorver conhecimento ou gozo, igualar-se em poder, ao que é de ordem sobre-humana, como o caso do "gênio" ou "espírito" evocado. Para além da Literatura e da Ciência, no mito de Fausto a alegoria do pacto com o demônio / renegação de Deus, implica também um contato com o metafísico. Geist é afinal o termo que aparece no

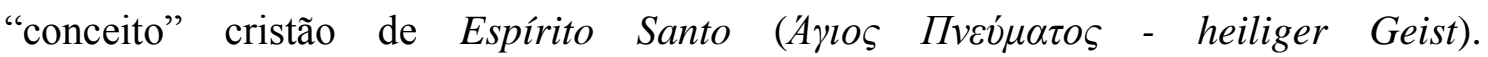
Etimologicamente próximo do ghost inglês, o vocábulo remete também às assombrações, ao desconhecido e unheimlich a ser temido e evitado, como no caso do nunca traduzido Poltergeist. Aladim, das Mil e uma noites, encontra também em sua lâmpada maravilhosa o Geist (Gênio), ente maravilhoso que pode conceder-lhe a realização de seus desejos. Mas também na tão racional filosofia o mais célebre tratado de Hegel versa sobre o Geist, sendo traduzido o título Phänomenologie des Geistes, ora como Fenomenologia do Espírito, ora como Fenomenologia da Mente. Por fim, no âmbito científico temos a famosa divisão proposta por Dilthey entre as Naturwissenschaften (Ciências Naturais) e as Geisteswissenschaften (Ciências Humanas/Ciências do Geist).

Com esse exemplo de um termo tão comum da língua alemã, podemos ter ideia de algumas das dificuldades que se impõem a um tradutor de Freud visando "apreenderlhe o espírito/gênio". Como ocorre com muitos outros intelectuais germanófonos - caso do mencionado Hegel -, Freud se utilizava geralmente de termos de uso cotidiano da língua numa trama teórica muito particular. No caso freudiano, algo semelhante se daria em relação aos seus usos do também fronteiriço (religião, filosofia, misticismo) vocábulo Seele. Praticamente equivalendo ao uso do vocábulo de origem grega Psyche $\left(\Psi v \chi \eta^{\prime}\right)$, numa tradução direta de Seele teríamos a palavra alma, que no português está tão comprometida com o discurso místico-religioso. Dificilmente Seele poderia equivaler no contexto científico ao parente etimológico soul na língua de Shakespeare. Mesmo assim, sabemos o quanto foi criticada a opção por mind (mente), na Standard Edition inglesa, sendo defendida até mesmo a opção por soul na polêmica levantada por Bruno Bettelheim (1983).

Retornaremos mais adiante aos conceitos-substantivos, mas, voltando à citação do Fausto, temos ali dois verbos - gleichen e begreifen - que aparecem de forma reiterada em suas variantes nessa obra máxima da cultura germanófona tão influente nas elaborações teóricas de Freud. Se é que números significariam algo em tal contexto, há 
Tavares, P. H. - Vocabulário metapsicológico de Freud

somente no Faust - Erster Teil (Primeira Parte) setenta e nove ocorrências de palavras com o étimo gleich e vinte e cinco com greif ou grif. No Zweiter Teil (Segunda Parte) chegam a cem as ocorrências para variantes de gleich e quarenta e oito para greif/grif (GOETHE 1996). Quer dizer, mais do que uma mera citação, a frase reproduz algo de essencial do drama e da personagem hibridística em questão, numa dicotomia que nos parece fundamental ao espírito epistemofílico de Freud.

Se a frase citada vem no início da Primeira Parte, lembremos que no segundo Fausto aparece o paradigmático episódio do Grifo (Greif) na Noite de Walpurgis clássica, que com suas garras nada apreendelagarra (greift) que lhe traga satisfação; passagem que nos remete à melancolia do velho Fausto no início do drama. Igualmente paradigmática seria a conclusão do drama, quando nos versos finais aparece também um derivado de gleich, a saber, Gleichnis (parábola, símile, metáfora).
Alles Vergängliche
Ist nur ein Gleichnis;
Das Unzulängliche,
Hier wird`s Ereignis;
Das Unbeschreibliche,
Hier ist`s getan;
Das Ewig-Weibliche
Zieht uns hinan.
[Tudo que transcorre
Não passa de um símile
O inacessível
Aqui torna-se fato
O indescritível
Aqui é elaborado
$\mathrm{O}$ eterno-feminino
Atrai-nos para si]

Se nesta tradução procuramos recuperar o semântico, maltratando tanto as outras facetas da poesia, é por que na própria tradução algo desse "inacessível” (das Unzulängliche), "indescritível" (das Unbeschreibliche) se manifesta na busca pelos "símiles" (Gleichnisse). Freud, com suas ideias e sua tradução em palavras, foi fáustico ao tentar fazer confluírem o gleichen (igualar/assemelhar) e o begreifen (apreender/compreender). Walter JENS usou como título a um importante trabalho seu sobre a escrita de Freud a expressão Ein jüdischer Faust (Um Fausto judeu), tamanha a 
Tavares, P. H. - Vocabulário metapsicológico de Freud

influência da personagem goethiana sobre o psicanalista e sua criação. A elaboração da imagem biográfica de Freud, tão diretamente relacionada à do herói pactário foi direta ou indiretamente analisada por vários autores conforme demonstrado em outra publicação nossa (Cf. TAVARES 2008).

MAHONY (1989), em seu livro Freud as a writer (Freud como escritor), trata dessa dupla natureza da escrita freudiana - espécie de cabeça de Jano - entre as capacidades estético-representacionais do gleichen e racionais-argumentativas do begreifen, ainda que para isso utilize em sua bela análise as noções verbais do mostrar e do fazer.

\begin{abstract}
A prosa de Freud não apenas dramatiza e reflete ela tem também valor racional e reflexivo. Mais do que qualquer outro analista, a prosa de Freud é bilateral, como o rosto de Jano, anfíbia, equilibrando-se entre mostrar e fazer, entre desempenho e descrição, refletindo e dando testemunho, processo primário e secundário, afeto e racionalidade, impulso e análise. Ela paira entre o consciente e o inconsciente é uma prosa limítrofe, por isso autenticamente "psicanalítica". Janela e espelho juntos constituem a imagem apropriada para caracterizar sua prosa especulativa. (MAHONY 1989: 59)
\end{abstract}

Mas um ponto fundamental no tocante ao verso extraído do Fausto e ao tema deste trabalho diz respeito à relação que se coloca entre o verbo begreifen (entender, apreender) e seu substantivo mais diretamente aparentado: Begriff, ou seja, conceito. Quer dizer, o vocábulo conceito (termo técnico) na língua de Freud denota uma busca de "agarrar" determinada noção (Vorstellung). Se levantamos a questão do estilo e vimos o quanto a sua obra é perpassada por Gleichnisse (símiles, parábolas, comparações), tão minuciosamente analisados na tese de ScHÖNAU (2006), certamente há também em seus escritos a preocupação com a elaboração de conceitos, ou Grundbegriffe (conceitos fundamentais) como os teria chamado. Ao conjunto desses Begriffe, à teoria psicanalítica, Freud teria dado o nome Metapsicologia (Metapsychologie).

Tendo o termo surgido já nos primórdios da Psicanálise, na correspondência com Wilhelm Fließ em 1896, ao eclodir a Grande Guerra em 1914, próximo dos seus sessenta anos e preocupado com o legado de uma concepção teórica, Freud elabora os planos de uma coletânea de doze trabalhos intitulados Zur Vorbereitung einer Metapsychologie. Dos doze idealizados, cinco artigos vieram a lume sob os títulos 
Tavares, P. H. - Vocabulário metapsicológico de Freud

individuais Triebe und Triebschicksale; die Verdrängung; Das Unbewusste; Metapsychologische Ergänzung zur Traumlehre e Trauer und Melancholie.

Meta-psicologia, o que está "além" da psicologia, refere-se ao ponto mais central de suas ideias: o Grundbegriff de Inconsciente (das Unbewusste). Se a Ciência Psicológica de seus contemporâneos havia feito da consciência seu objeto de estudos, ao relegá-la, a consciência, à condição de um secundário epifenômeno, Freud visa fausticamente investigar cientificamente o Aqueronte, o "além-mundo" da Psicologia científica. Lembremos aqui da célebre epígrafe de sua "obra mestra", Die Traumdeutung, [A interpretação dos sonhos] (1900): "Flectere si nequo superos, aqueronta movebo", extraída da Eneida de Virgílio. Uma tradução possível seria "Se não posso dobrar as esferas superiores, moverei o Aqueronte", adaptando tal ideia a um símile cristão: "Se não posso tocar o celestial, moverei os infernos". Seu pacto será, logo, com tudo o que foi relegado das esferas superiores da respeitada Ciência Positiva: sonhos, atos falhos, sexualidade, fantasias, humor, loucura, desejos infantis. Sua blasfêmia estaria em fazer que se comunicassem os apartados mundos do científico e do literário.

Se com o advento da noção de Metapsicologia poderíamos pensar finalmente em uma face de Freud, cujo comprometimento com o científico o afastasse dos símiles literários, vale aqui a já tão célebre comparação feita pelo autor entre seu sistema teórico e a bruxa/feiticeira (Hexe), personagem do Fausto de Goethe. Trata-se de uma passagem de Die endliche und die unendliche Analyse, na qual o psicanalista trata do problema da "domação da pulsão" (Bändigung des Triebes), momento da argumentação no qual haveria uma aparente contradição entre aspectos destrutivos e harmonizadores entre a pulsão (Trieb) e o Eu (Ich). Diante do leitor, Freud admite sua dificuldade em se ater aos limites tradicionais da metodologia científica. Ali ele diretamente cita sem mencionar a fonte, subtendendo a familiaridade do leitor com a passagem do drama: "Deve-se, então, contar com a bruxa/feiticeira" (So muss denn doch die Hexe dran), ao que acrescenta, "a saber, a bruxa Metapsicologia" (Die Hexe Metapsychologie nämlich) (FREUD 1937: 69).

Freud vai além em sua postura que desafia os ditames da ciência aproximando até mesmo sua doutrina da fantasia ou do devaneio: “Ohne Metapsychologisches Spekulieren und Theorisieren - beinahe hätte ich gesagt: Phantasieren - kommt man 
Tavares, P. H. - Vocabulário metapsicológico de Freud

hier keinen Schritt weiter. Leider sind die Auskünfte der Hexe auch diesmal weder noch klar noch sehr unschätzbar" (Id.) [Sem especulação e teorização metapsicológicas quase diria: fantasiar/devanear - não se consegue aqui sequer dar um passo adiante. Infelizmente as informações da bruxa não são também desta vez nem tão claras nem tão minuciosas.]

MusCHG (1930), novamente mostrando a singular posição de Freud entre o científico e o literário, afirma que Freud teria usurpado a palavra "sonho" (Traum) dos poetas. O que não diz é que o psicanalista a submeterá a uma sintaxe ou gramática da ciência em enunciados tais como "Der Traum ist die (verkleidete) Erfüllung eines (unterdrückten/verdrängten) Wunsches" (O sonho é a realização [disfarçada] de um desejo [reprimido/recalcado]) (1900: 166), afirmação tão próxima em forma da axiomática "A soma dos quadrados dos catetos é igual ao quadrado da hipotenusa". Quer dizer, ele faz por vezes uso de um léxico literário numa sintaxe científica em ocasiões como essa, enquanto nos seus casos clínicos (Krankengeschichten) apresentará toda a descrição dos sintomas com conceitos em preciso Medizinerdeutsch (alemão “medicinal"), porém dentro de uma tão elaborada estrutura narrativa, que cativará leitores interessados nas qualidades literárias desses historiais, lidos como verdadeiros romans-à-clefs.

No primeiro dos Artigos sobre Metapsicologia, destinado ao conceito de Trieb, teria deixado claro que mesmo procurando a maior objetividade possível, seus Grundbegriffe são conceitos inexatos em constante re-elaboração, e assim adverte seu leitor:

Wir haben oftmals die Forderung vertreten gehört, dass eine Wissenschaft über
klaren und scharf definierten Grundbegriffen aufgebaut sein soll. In
Wirklichkeit beginnt keine Wissenschaft mit solchen Definitionen, auch die
exaktesten nicht. Der richtige Anfang der wissenschaftlichen Tätigkeit besteht
vielmehr in der Beschreibung von Erscheinungen, die dann weiterhin gruppiert,
angeordnet und in Zusammenhänge eingetragen werden. (1915: 81)

[Com frequência ouvimos a exigência de que uma Ciência deve ser erigida sobre conceitos fundamentais claros e precisos. Na realidade nenhuma Ciência, nem mesmo a mais exata, começa com tais definições. $\mathrm{O}$ verdadeiro princípio da atividade científica consiste sobretudo na descrição de fenômenos, que então posteriormente são agrupados, organizados e dispostos em determinada correlação.] 
Tavares, P. H. - Vocabulário metapsicológico de Freud

É curioso que tenha começado a sua coletânea, justamente com o seu conceito fundamental de definição mais fugidia e de mais difícil apreensão: o Trieb. Trata-se afinal de uma noção cujas concepções viriam a sofrer uma grande reviravolta em Jenseits des Lustprinzips (1920), publicado dois anos após o final da guerra. Não à toa parece ser esse também o conceito, cuja tradução até hoje mais determinantemente marca as divisões entre os psicanalistas e demais leitores de Freud. O que estes acabam muitas vezes por querer esquecer é o quanto, mesmo na obra do autor, seus conceitos eram um work in progress que provavelmente não terminou com a obra por ele legada.

\begin{abstract}
Erst nach gründlicher Erforschung des betreffenden Erscheinungsgebietes kann man auch dessen wissenschaftliche Grundbegriffe schärfer erfassen und sie fortschreitend so abändern, dass sie in großem Umfange brauchbar und dabei durchaus widerspruchsfrei werden. Dann mag es auch an der Zeit sein, sie in Definitionen zu bannen. Der Fortschritt der Erkenntnis duldet aber auch keine Starrheit der Definitionen. Wie das Beispiel der Physik in glänzender Weise lehrt, erfahren auch die in Definitionen festgelegten "Grundbegriffe" einen stetigen Inhaltswandel (FREUD 1915: 81).
\end{abstract}

[Somente após uma exploração dos fundamentos no campo dos fenômenos em questão pode-se apreender de modo mais preciso os seus conceitos fundamentais científicos e progressivamente alterá-los de modo que sejam úteis em um âmbito maior, tornando-se assim livres de contradições. Pode então chegar o momento para encaminhar tais conceitos às definições. Entretanto, o progresso do conhecimento não tolera nenhuma rigidez de definições. Como nos ensina de modo fulgurante o exemplo da Física, mesmo as definições dos "conceitos fundamentais" rigidamente estabelecidos, sofrem uma constante modificação de seus conteúdos.]

Quer dizer, tratar de uma terminologia, ou terminografia freudiana traz em si o complicador de abordarmos "termos" que não encontraram seu "termo" no processo de sua elaboração. Como apontávamos alhures (TAVARES 2011: 23), em português termo não somente é anagrama de morte como também divide com a última palavra a acepção de algo findado, pronto, acabado.

Tais considerações são fundamentais como prevenção ao nos aproximarmos do vocabulário freudiano, mas isso certamente não resolve o problema de leitores que buscam a maior clareza possível em seus escritos, sobretudo dos que o leem para fundamentarem teoricamente uma prática clínica, e que procurem a descrição mais precisa e inequívoca possível dos conceitos fundamentais forjados pelo fundador da Psicanálise. Eis aí a necessidade de uma terminografia psicanalítica, entendendo-se esta como "uma prática de elaboração de vocabulários técnicos, científicos, especializados" 
Tavares, P. H. - Vocabulário metapsicológico de Freud

(BARROS 2005: 68). O primeiro intento nesse sentido se deu na própria língua alemã sob a coordenação de Richard STERBA, que iniciou seus trabalhos no Handwörterbuch der Psychoanalyse (dicionário "manual” da Psicanálise) em 1931, sendo interrompido em 1938 quando a redação, progredindo em ordem alfabética, encontrava-se na letra L (apud ROUDINESCO \& PLON 1997: VII).

Em decorrência da eclosão da segunda guerra e do falecimento de Freud um ano mais tarde, tal como aliás ocorreu com a organização e publicação de suas obras, os grandes léxicos de Psicanálise vieram a ser redigidos em inglês e francês e não no alemão, na língua a partir da qual Freud formulou suas proposições e da qual retirou seus Grundbegriffe. No ano de 1968, trinta anos após a interrupção do intento inaugural de Sterba, vimos surgir três influentes léxicos em língua inglesa e um, talvez o mundialmente mais influente, em língua francesa. Nos Estados Unidos a American Psychoanalytical Association, através de M. D. MoOrE e D. Bernard FINE, apresenta com A Glossary of Psychoanalytic Terms and Concepts, segundo ROUDINESCO \& PLON, um freudismo "pragmático e medicalizado" (idem, p. VIII). No mesmo ano Ludwig EIDELBERG, austro-húngaro refugiado nos Estados Unidos, organiza sua Encyclopedia of Psychoanalysis e Charles RYCROFT lança na Inglaterrra A Critical Dictionary of Psychoanalysis. No tocante aos franceses, em 1968 surge o Vocabulaire de la Psychanalyse, projeto iniciado por Daniel LAGACHE, mas levado a cabo por Jean LAPLANCHE e Jean Bertrand PONTALIS.

Voltaremos, sobretudo, ao último dos léxicos citados, mas caberia aqui mencionarmos talvez aquele que, mesmo sem uma grande pretensão lexicográfica de apontar definições para a "terminologia" freudiana, teve uma influência capital para a difusão de sua obra a partir de suas traduções. Falamos do Glossary for the use of translators of psycho-analytical works, organizados por Ernest JONES e publicado em Londres em 1924 no International Journal or Psycho-Analysis.

Ernest Jones foi afinal o grande responsável pela organização daquela que seria a edição mais divulgada e influente das obras de nosso autor: a Standard Edition inglesa. Mesmo tendo como principal tradutor James STRACHEY, a edição e, como seu nome indica, o fato de ter se tornado um modelo (standard) para o freudismo, deve seus méritos e críticas fundamentalmente a Jones, o grande político da Psicanálise após a morte de seu fundador. $\mathrm{O}$ fato de Freud ter se exilado em Londres no último ano de sua 


\section{Tavares, P. H. - Vocabulário metapsicológico de Freud}

vida e de lá ter encontrado refúgio para sua família e seus escritos ajuda-nos a compreender parte da influência que teve a língua inglesa na difusão de sua terminologia. Mas a isso certamente se soma o fato de que não somente na Inglaterra, mas sobretudo nos Estados Unidos, grande potência emergente no pós-guerra, houve uma avidez pelo o legado sobre uma promissora e lucrativa prática clínica.

BETTELHEIM (1983) e LACAN (1964), entre muitos outros, criticarão o crivo cientificista - voltado sobretudo para uma Medicina ou Psicologia tecnocráticas - pelo qual passaram a recepção dos textos e os conceitos fundamentais da Psicanálise entre os anglófonos. Apesar de Freud ter escrito Die Frage der Laienanalyse [A questão da análise leiga], como declarara, para proteger a Psicanálise do domínio dos médicos (FREUd 1928 apud BETTELHEIM 1989), seu destino na grande potência do novo mundo será o de incorporar-se à Ciência Médica, destino que teve grande amparo no viés que sua tradução sofreu para a língua inglesa. No mesmo ensaio, aliás, aparece a preocupação com a compreensão de seus conceitos por parte dos beneficiários do método terapêutico por ele criado (seus pacientes), mais do que simplesmente por uma restrita e fechada comunidade de iniciados em seus estudos (os psicanalistas).

O uso de termos coloquiais, de uso cotidiano, é uma das principais marcas distintivas do vocabulário freudiano quando comparado aos inúmeros teóricos do psiquismo que o sucedem. Como aponta Uwe PÖRSKEN em seu estudo Zur Terminologie der Psychoanalyse, publicado em 1973, nosso autor se distancia da proposição de um jargão para iniciados, sem abrir mão de uma descrição comprometida com precisão e clareza:

\footnotetext{
Freud em geral escreve não em uma linguagem especial, que pressuponha o conhecimento de um jargão, mas em uma linguagem culta (Bildungssprache), "na qual se serve de expressões usuais da 'língua natural', esclarecendo os termos técnicos à medida que os introduz, parafraseando-os, tornando-os transparentes no contexto da exposição. Aí estaria, então, a maior peculiaridade do seu estilo: no fato de usar uma terminologia própria, mas não escrever "terminologicamente" (apud SouZA 1999: 71)
}

Essa característica tão distintiva da escrita freudiana começou a ser dissipada a partir das proposições de traduções de seu vocabulário fundamental para a língua inglesa. $\mathrm{O}$ pioneirismo de Jones na "standartização" da terminologia psicanalítica levou-o ao recurso universalizante às "línguas mortas", línguas que tanto servem historicamente à 
Tavares, P. H. - Vocabulário metapsicológico de Freud

Terminologia. Haja vista aqui o feito do naturalista Karl von Linné (Lineu) e sua sistematização para a nomenclatura das espécies (Botânica e Zoologia) a partir das designações binomiais greco-latinas. Assim como a Medicina se vale do grego antigo ou do latim para nomear suas entidades clínicas em casos como pneumonia, glossite, xeroftalmia, Jones propõe, desde seu Glossary de 1924, um caminho semelhante para vocábulos freudianos com sentidos muito "vivos" e de direto acesso para os falantes da língua alemã. Assim, os pronomes pessoais Ich (eu) e Es (isso) passaram a se chamar Ego e Id; a Besetzung (ocupação, investimento) da libido tornou-se cathexis; as Fehlleistungen (realizações falhas/atos falhos) tornaram-se parapraxis; além do mais o forçoso caso do uso de instinct para verter Trieb.

$\mathrm{Na}$ França foi considerável a oposição aos rumos que a Psicanálise teve nos países de língua inglesa e a aderência da Psicanálise à Medicina e ao discurso das Ciências Naturais. No sentido terminográfico, entretanto, ao "libertar" a Psicanálise das amarras da Medicina, ironicamente se fez pendê-la para uma nova aderência: ao discurso filosófico. Filósofos de formação, Jean LAPLANCHE e Jean-Bertrand PoNTALIS organizaram o mais influente léxico internacional da Psicanálise sob forte influência do modelo do Vocabulaire technique et critique de la Philosophie de André LALANDE. Trata-se do há pouco mencionado Vocabulaire de la Psychanalyse de 1968. Não somente pela proximidade de seus autores com o lacanismo, o léxico se tornará uma referência sobretudo em países como o Brasil, que careciam de uma boa tradução das obras de Freud. O peso de sua influência internacional se deve principalmente ao fato de apresentar uma minuciosa busca por uma definição inequívoca dos conceitos freudianos e alternativas de tradução aos vocábulos em cinco línguas europeias modernas, a saber: francês, alemão, inglês, espanhol e português.

Certamente em decorrência do prestígio de que gozava o léxico, um de seus autores, Jean Laplanche, ao lado de Pierre Cotet e André BourguignON, será o encarregado pela coordenação do primeiro projeto de tradução sistemática das obras completas de Freud para o francês. No Vocabulaire se percebe a clara influência da leitura francesa do vocabulário filosófico de língua alemã como uma espécie de terminologia fechada, monossêmica e novamente distanciada da experiência comum e cotidiana. Veja-se o caso da tradução de Angst (medo/angústia/ansiedade) invariavelmente por angoisse; de Vorstellung (representação/ideia/noção), 
Tavares, P. H. - Vocabulário metapsicológico de Freud

invariavelmente vertida por représentation ou de neologismos dispensáveis como étayage para Anlehnung ou désaide para Hilflosigkeit.

No Brasil, na busca por uma versão adequada para o vocabulário freudiano permanecemos até recentemente à mercê das opções de Jones e Strachey, através do que se reproduziu na Standard Brasileira, ou das opções de Laplanche e Pontalis, com a tradução do "internacional" Vocabulaire. Na busca por ultrapassar tais barreiras, muito comumente se observam leitores brasileiros de Freud fazendo uso das duas disponíveis versões das obras completas em castelhano. Nesse sentido, aliás, os hispano-hablantes estariam muito mais bem amparados que os falantes de português.

Dispõe-se afinal, na língua de Cervantes, tanto de uma tradução de grande qualidade literária, que faz jus ao grande escritor Freud, quanto de uma tradução de elevado primor epistêmico, mais preocupada com o rigor terminológico. A primeira, iniciada em 1922 e que mereceu os elogios de Freud redigidos em espanhol, esteve a cargo de BALLESTEROS e DE TORRES, na Espanha. Como lhe pesavam críticas quanto à falta de atenção a critérios terminológicos, em 1978 o argentino Luis ETCHEVERRY encarrega-se de elaborar uma nova tradução direta, cujo foco seria justamente a precisão e o rigor. Como talvez não pudesse deixar de ser, fazendo-se pender para a precisão, a versão de Etcheverry será acusada de excessos tecnicistas ou filosóficos.

O curioso, porém, é que mesmo que na nossa "língua-irmã" exista a oportunidade de acesso a duas versões diretas do alemão, é indiscutível o grande peso que o Glossary de Jones teve sobre a versão de Ballesteros, ao passo que o Vocabulaire de Laplanche e Pontalis influenciou fortemente a versão de Etcheverry, como se pode verificar na tabela abaixo. Isso vale como ponto fundamental de reflexão sobre a pregnância que têm as versões inglesa e francesa no cenário psicanalítico internacional, independentemente de sua acuidade. Não seria exagero dizer que em muitos casos essas línguas foram mais influentes na difusão da terminologia freudiana do que o próprio alemão dos escritos originais. 
Tavares, P. H. - Vocabulário metapsicológico de Freud

\begin{tabular}{|l|l|l|l|l|}
\hline Freud (Original) & $\begin{array}{l}\text { Standard Edition } \\
\text { (Inglaterra) }\end{array}$ & $\begin{array}{l}\text { Obras Completas } \\
\text { (Espanha) }\end{array}$ & $\begin{array}{l}\text { Vocabulaire / } \\
\text { Euvres Complètes } \\
\text { (França) }\end{array}$ & $\begin{array}{l}\text { Obras } \\
\text { Completas } \\
\text { (Argentina) }\end{array}$ \\
\hline Anlehnung & anaclisis & anaclisis / apoyo & étayage & apuntalamiento \\
\hline Besetzung & cathexis & catexia & investissement & investidura \\
\hline Regung & impulse & exitación / impulso & motion & moción \\
\hline Trieb & instinct & instinto & pulsion & pulsión \\
\hline Triebregung & instinctual impulse & $\begin{array}{l}\text { instinto / impulso } \\
\text { instintivo }\end{array}$ & motion pulsionelle & $\begin{array}{l}\text { moción } \\
\text { pulsional }\end{array}$ \\
\hline Unterdrückung & suppression & supresión & répression & sofocasión \\
\hline Vorstellung & ideia & $\begin{array}{l}\text { representación, } \\
\text { idea }\end{array}$ & représentation & representación \\
\hline $\begin{array}{l}\text { Vorstellungs- } \\
\text { repräsentanz }\end{array}$ & $\begin{array}{l}\text { ideational } \\
\text { representative }\end{array}$ & $\begin{array}{l}\text { representación } \\
\text { ideológica }\end{array}$ & $\begin{array}{l}\text { représentant- } \\
\text { représentation }\end{array}$ & $\begin{array}{l}\text { representante- } \\
\text { representación }\end{array}$ \\
\hline
\end{tabular}

Quanto ao Brasil, com a prescrição dos direitos autorais sobre a obra de Freud em 2009, vemos finalmente surgirem versões diretas ao português como é o caso da tradução coordenada por Paulo César de Souza (Cia. das Letras), Luiz Alberto Hanns (Ed. Imago), Renato ZWICK (L\&PM), bem como dos textos traduzidos na década de 1980 por Marilene CARONE (Cosac \& Naify). Certamente outras versões a cargo de outros tradutores deverão surgir nos próximos anos, mas se observa uma atenção especial às duas primeiras mencionadas por serem Souza e Hanns, além de tradutores, importantes estudiosos da escrita freudiana ao longo das últimas décadas, tendo ambos dedicado suas teses de doutorado ao assunto e publicado importantes livros e artigos a respeito da temática.

Com relação às tão difundidas influências inglesas e francesas, poder-se-ia se dizer o seguinte a respeito do rumo dado por Souza às traduções dos conceitos metapsicológicos desde sua tese publicada sob o título Palavras de Freud - o vocabulário freudiano e suas versões. O tradutor se mostra um ferrenho crítico, sobretudo da inflexibilidade da tradução coordenada por Laplanche e tão próxima do Vocabulaire de la Psychanalyse, do qual é co-autor. Para Souza a opção inequívoca pela equivalência entre termos alemães e franceses seria a grande fragilidade das propostas francesas. Critica igualmente na tradução francesa o recurso a neologismos desnecessários e à ilegibilidade decorrente da opção por uma tradução termo a termo, gerando no francês estranhas construções sintáticas. 
Tavares, P. H. - Vocabulário metapsicológico de Freud

Por outro lado, grande admirador do feito de Strachey como tradutor, Souza se apropriará de cognatos de origem latina na língua portuguesa em muitas das soluções da Standard inglesa. Serão os casos de repression (repressão), suppression (supressão), civilization (civilização), e até mesmo o tão polêmico instinct (instinto) para traduzir o Trieb. Quanto aos "neologismos clássicos" sugeridos por Jones, no entanto, Souza os recusa, procurando alguma equivalência no vocabulário comum da língua portuguesa, traduzindo assim Anlehnung por apoio, Besetzung, por investimento e Fehlleistung por ato-falho, para retornarmos aos exemplos anteriormente citados.

Luiz Alberto Hanns, conforme demonstrado em Versões de Freud (TAVARES, 2011) diferentemente do viés dado por Souza, tão preocupado com o resgate do escritor Freud é, por sua vez, um grande estudioso justamente de seu vocabulário fundamental. Por isso afirmamos ser Souza um mestre do sintagmático, na sua hábil retextualização das frases e do estilo freudianos, ao passo que Hanns seria um mestre do paradigmático, na sua cuidadosa relação com a terminologia do autor. Quanto a Hanns, sua grande contribuição nesse sentido foi o criterioso Dicionário comentado do alemão de Freud de 1996, no qual busca familiarizar o leitor de língua portuguesa com as especificidades dos vocábulos coloquiais utilizados por Freud em sua empresa teórica tais como Lust, Reiz, Trieb, Angst, Drang etc.

Como tradutor, no entanto, Hanns, muito diferentemente de Souza e de sua maior proximidade das opções difundidas através da edição inglesa, fará uso de opções mais difundidas no meio psicanalítico brasileiro. Indiretamente, portanto, dada a forte influência do lacanismo e do léxico de Laplanche e Pontalis no meio especializado em estudos freudianos, suas opções de tradução muitas vezes se aproximam muito das opções francesas. Nesse sentido, ele opta pelo uso de pulsão para traduzir Trieb; e recalque, para Verdrängung, destinando repressão para a tradução de Unterdrückung. Não adere, entretanto, à tradição lacaniana de traduzir Verwerfung por forculsão, preferindo rejeição, ou de verter Phantasie por fantasma, propondo fantasia.

Um dado curioso, porém, está no destino dado por ambos os tradutores às instâncias da segunda tópica Ich e Es. Através da influência da Standard popularizou-se no Brasil o uso dos termos latinos Ego e $I d$, respectivamente, para sua tradução. Opondo-se a essa solução e comprometidos com o retorno à coloquialidade freudiana, muitos psicanalistas brasileiros fazem uso dos relativos pronomes Eu e Isso para vertê- 
Tavares, P. H. - Vocabulário metapsicológico de Freud

los. Estranhamente, Hanns e Souza parecem aí terem se encontrado nos interstícios. Ambos se valem do pronome pessoal Eu para o Ich freudiano, ainda que permaneçam com a popularizada solução da Standard na tradução de Es por Id.

\begin{tabular}{|c|c|c|c|c|}
\hline $\begin{array}{l}\text { Freud } \\
\text { (Original) }\end{array}$ & $\begin{array}{l}\text { Standard Edition } \\
\text { (Inglaterra) }\end{array}$ & $\begin{array}{l}\text { Paulo César de } \\
\text { Souza }\end{array}$ & $\begin{array}{l}\text { Euvres Complètes } \\
- \\
\text { (França) }\end{array}$ & $\begin{array}{l}\text { Luiz Alberto } \\
\text { Hanns }\end{array}$ \\
\hline Angst & anxiety (fear) & medo / angústia & angoisse & medo / angústia \\
\hline Anlehnung & anaclisis & apoio & étayage & $\begin{array}{l}\text { veiculação } \\
\text { sustentada }\end{array}$ \\
\hline Besetzung & cathexis & investimento & investissement & investimento \\
\hline Es & id & id & ça & id \\
\hline Ich & ego & eu & moi & eu \\
\hline Kultur & civilization & civilização & culture & cultura \\
\hline Regung & impulse & impulso & motion & moção/ impulso \\
\hline Seele & mind & alma/psique & âme & psique / alma \\
\hline seelisch & mental & psíquico / anímico & animique & psíquico \\
\hline Trieb & instinct & instinto & pulsion & pulsão \\
\hline Triebregung & instinctual impulse & $\begin{array}{l}\text { impulso instintual / } \\
\text { instinto }\end{array}$ & motion pulsionelle & $\begin{array}{l}\text { moção pulsional } \\
\text { / pulsão que } \\
\text { acaba de brotar }\end{array}$ \\
\hline$\ddot{U ̈ b e r-I c h}$ & superego & super-eu & sur-moi & supraeu \\
\hline Unterdrückung & suppression & supressão & répression & repressão \\
\hline Verdrängung & repression & repressão & refoulement & recalque \\
\hline Vorstellung & ideia & ideia & représentation & representação ${ }^{8}$ \\
\hline
\end{tabular}

De fato, as influências das tradições estrangeiras na difusão do vocabulário freudiano no Brasil contribuíram para um decorrente "enrijecimento" do texto de um autor cujo pensamento emanava tanta vitalidade. Na recuperação dessa característica parece estar, aliás, o mérito das ainda poucas traduções elaboradas por Renato ZwICK. No caso da língua de Freud e dos usos feitos pelo autor, essa é uma "língua viva" que serve de modo particular a tratar da experiência cinestésico-corporal, para muito além do Körper (corpo anatômico, corpo morto e dissecado), para algo mais próximo do que o alemão designa pelo vocábulo Leib (corpo vivo e sensorial). O conceito de Trieb, particularmente, no já citado ensaio metapsicológico Triebe und Triebschicksale, é

\footnotetext{
${ }^{8}$ Forma mais utilizada pelo tradutor, que aponta alternativas como ideia, imagem, concepção, etc.
} 
Tavares, P. H. - Vocabulário metapsicológico de Freud

apresentado como um conceito-limite (Grenzbegriff) entre o corporal e anímico (seelisch).

Pois justamente um investigador das relações de Freud com a língua alemã, Georges-Arthur GOLDSCHMIDT é quem nos aponta sua impressão do quanto a intelectualidade que se expressa através do alemão teria a seu dispor uma língua particularmente voltada à experiência concreta e espacial, que de modo privilegiado traduz algo entre os planos psíquico e corporal. Para o tradutor e ensaísta francoalemão, "[q]uanto mais a filosofia alemã se faz profunda, mais seu vocabulário é simples e concreto, ou próximo fundamentalmente deste leibliche Befinden, desta localização do corpo mesmo" (GOLDSCHMIDT 1988: 17). Como afirmara o próprio Wilhem von Humboldt, "é sempre a partir deste ponto de vista cinestésico que se organiza a língua alemã" (apud GOLDSCHMIDT 1988: 17).

Isso nos remete ao início da Psicanálise, às descobertas de Breuer e de Freud quanto aos mecanismos da conversão histérica. No corpo (Leib) histérico, no corpo vivo e pulsante, o linguageiro ganhava vida e a palavra se traduzia em carne. A partir da concepção de que um mal físico tinha origem no psíquico, através de um "represamento" simbólico no corpo, Freud e Breuer percebem que é pelas palavras, por uma técnica baseada na fala (talking cure) que o represamento cessa e se restabelece um "fluir" rumo à purgação. Observando as capacidades do alemão em representar tal situação, assinalam: "Unsere Sprache bezeugt diese Tatsache der täglichen Beobachtung durch die Ausdrücke 'sich austoben, sich ausweinen"”. [Nossa língua comprova este fato da observação cotidiana através das expressões 'esvair-se em cólera' ou 'esvair-se pelo choro'] (FreUd \& BREUER 1893: 87). Poucas linhas adiante, no mesmo texto, assinalam a relação que em alemão se manifesta entre uma ofensa (Kränkung) sofrida e o tornar-se doente (krank).

Outra autora fundamental nas discussões sobre os usos freudianos da língua alemã é Janine ALtounian (2003), que fundamenta suas observações sobre os elementos de dinamismo no vocabulário freudiano a partir de uma hipótese curiosa: teriam relação com a experiência de constante deslocamento forçado a que teriam sido submetidos Freud e seus familiares dada a sua ascendência judaica. Concordando-se ou não com Goldschmidt ou Altounian, é inegável o quanto podemos observar no dinamismo, na já mencionada vivacidade da prosa freudiana, por um lado, os vocábulos 
Tavares, P. H. - Vocabulário metapsicológico de Freud

relacionados ao fluir, transcorrer (Übertragung, Vorgang, Bahnung, Verschiebung etc.) e, por outro, os relacionadas às forças de imposição (Trieb, Zwang, Drang, Verdrängung, Unterdrückung).

Se tanto no alemão quanto no português o "domínio" de uma língua estrangeira é representado pela noção de "fluência", que sejam as novas e diretas traduções de Freud uma nova oportunidade para que seu vocabulário ultrapasse o represamento dos léxicos e volte ao seu livre fluxo nas leituras do público brasileiro.

\section{Referências}

Altounian, Janine. L'écriture de Freud - Traversée traumatique et traduction. Paris : Presses Universitaires de France, 2003.

BARros, Lidia Almeida. Curso Básico de Terminologia. São Paulo: EdUSP, 2004.

BeTtELHEIM, Bruno. Freud and man's soul. Nova Iorque: Knopf, 1983.

BRACCO, Mariangela Oliveira Kamnitzer. Freud e o Prêmio Goethe. J. psicanal. [online]. 2011, vol.44, n.81 [citado 2012-07-15], pp. 253-258.

FREUD, Sigmund. Gesammelte Werke - Chronologisch geordnet. Frankfurt am Main: Fischer Verlag, 1999. - Der Goethe-Preis (1930) - Die endliche und die unendliche Analyse (1936) - Die Traumdeutung (1900) - Studien über Hysterie (1893) - Triebe und Triebschicksale (1915) - Über die Psychotherapie (1905)

GoETHE, Johann Wolfgang. Faust I und II. Colônia: Könnemann, 1996.

GOLDSCHMIDT, Georges-Arthur. Quand Freud voit la mer - Freud et la langue allemande 1. Paris: Buchet-Chastel, 1988.

HANNS, Luiz Alberto. Dicionário comentado do alemão de Freud. Rio de Janeiro: Imago, 1996.

JENS, Walter. Ein jüdischer Faust. Portal do jornal Die Zeit. Disponível em: http://www.zeit.de/1961/08/ein-juedischer-faust. Acesso em 02/02/2011.

LACAN, Jacques. Du "Trieb" de Freud et du désir du Psychanalyste. in Écrits II, Paris: Éditions du Seuil, 1964/1999.

LaPlanche, J. \& Pontalis J.-B. Vocabulário da Psicanálise. Tradução de Pedro Tamen. São Paulo: Martins Fontes, 1968/2001.

MAHONY, Patrick. Freud as a Writer. Nova Iorque: Yale University Press, 1987.

MANN, Thomas. Freud und die Zukunft in Adel des Geistes. Frankfurt am Main: Fischer 1955.

MusCHG, Walter. Freud als Schriftsteller. In Die Zerstörung der deutschen Literatur. Berna: Diogenes. 2009.

RoudinesCo, Elisabeth \& PLON, Michel. Dicionário de Psicanálise. Tradução de Vera Ribeiro e Lucy Magalhães. Rio de Janeiro: Jorge Zahar Editor, 1997.

SCHÖNAU, Walter. Sigmund Freuds Prosa - Literarische Elemente seines Stils. Giessen: Psychosozial-Verlag, 2006.

SouZA, Paulo César de. As palavras de Freud - O vocabulário freudiano e suas versões. São Paulo: Ática, 1999. 
Tavares, P. H. - Vocabulário metapsicológico de Freud

TAVARES, Pedro Heliodoro. O mito de Fausto na construção da imagem biográfica de Freud. Acheronta - Revista de Psicoanálisis y Cultura [online]. 2008, vol. 25.

TAVARES, Pedro Heliodoro. Versões de Freud - Breve panorama crítico das traduções de sua obra. Rio de Janeiro: 7Letras, 2011.

Recebido em 02 de agosto de 2012

Aprovado em 26 de setembro de 2012 